\title{
Chylothorax, chylopericardium and lymphoedema - the presenting features of signet-ring cell carcinoma
}

\author{
N. Mogulkoc*, B. Önal**, N. Okyay*, Ö. Günel**, Ü. Bayindir*
}

Chylothorax, chylopericardium and lymphoedema - the presenting features of signet-ring cell carcinoma. N. Mogulkoc, B. Önal, N. Okyay, Ö. Günel, Ü. Bayindir. C)ERS Journals Ltd 1999.

ABSTRACT: This report describes a patient with chylous pleural and pericardial effusions in conjunction with severe lymphoedema resembling elephantiasis. The chylous effusions and generalized lymphoedema were associated with a signet-ring cell carcinoma.

Eur Respir J 1999; 13: 1489-1491.
Depts of *Pulmonary Disease and **Pathology, University of Ege, Bornova, Izmir, Turkey.

Correspondence: N. Mogulkoc, North West Lung Research Center, Wythenshawe Hospital, Southmoor Road, Wythenshawe, Manchester M23 9LT, UK. Fax: 44 1612915054

Keywords: Carcinoma, chylopericardium, chylothorax, lymphoedema

Received: June 251998

Accepted after revision October 101998
Chylothorax is a relatively uncommon condition, occasionally complicating cardiac and general thoracic surgical procedures [1-4]. Oedema of the lower extremities and body wall can arise from increased capillary permeability or obstruction of the lymphatic channels and an imbalance between capillary filtration and lymph drainage [5, 6]. Chronic lymphoedema in association with chylous effusions rarely occurs. One such case associated with a signet-ring cell carcinoma is described.

\section{Case report}

A 19-yr-old female university student presented with a 1.5-yr history of slowly progressive, diffuse lymphoedema of the whole body. The oedema extended from the feet to below the neck. She gave a history of weight gain of $\sim 30$ $\mathrm{kg}$ over the preceding 12 months. Previous treatment with elevation of the lower extremities, the use of elastic stockings and administration of diuretics had not been helpful in this patient. She also reported a 2-month history of progressive shortness of breath, fatigue and dry cough. She was a nonsmoker, and her family history was unremarkable (fig. 1).

Clinical examination on presentation revealed a patient with extensive nonpitting oedema of the skin, diminished breath sounds and dullness to percussion posteriorly. A cardiac examination was normal. There was no lymphadenopathy. The diagnosis of lymphoedema was confirmed by lymphoscintigraphy. ${ }^{99 \mathrm{~m}}$ Tc-labelled human serum albumin was injected intradermally into the medial web of the dorsum of each foot. The uptake of isotope by lymph nodes was reduced in the right side, with no uptake by nodes above the inguinal region. There was marked stasis, with total occlusion of the lymph channels at the level of the dorsum of the left foot. By contrast, phlebography was normal.

Chest radiography and thoracic computed tomography (CT) revealed bilateral pleural and pericardial effusions.
No parenchymal abnormality or mediastinal lymph nodes were observed. An echocardiogram demonstrated a small pericardial effusion. Thoracocentesis of the left- and rightsided effusions demonstrated a white odourless fluid with a

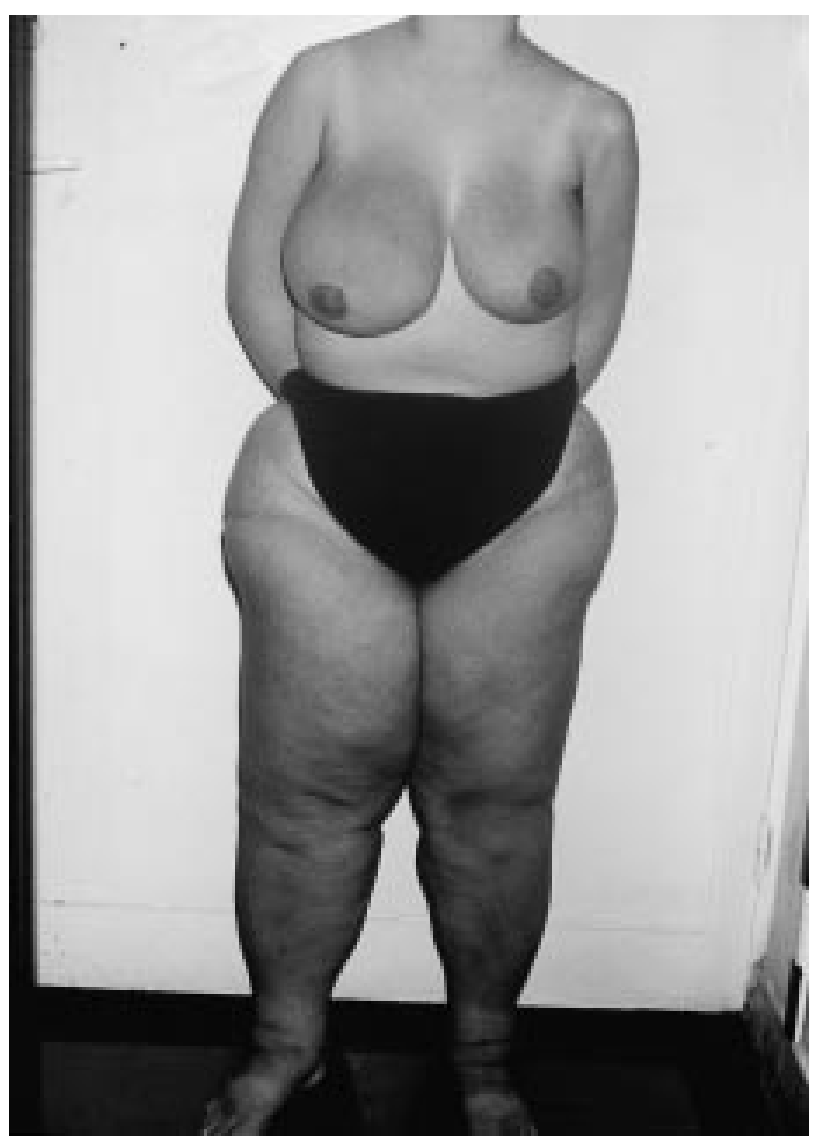

Fig. 1. - Elephantiasis-like chronic severe lymphoedema of the extremities and body wall. 
milky appearance. Biochemical analysis revealed a triglyceride concentration of $335 \mathrm{mg} \cdot \mathrm{dL}^{-1}$ (serum 120, normal 30-150), total cholesterol of $59 \mathrm{mg} \cdot \mathrm{dL}^{-1}$ (serum 108, normal 100-200), total protein of $2.8 \mathrm{~g} \cdot \mathrm{dL}^{-1}$ (serum 5.9, normal 6.0-8.5), glucose of $80 \mathrm{mg} \cdot \mathrm{dL}^{-1}$ (serum 74, normal $60-100)$ and lactate dehydrogenase of $230 \mathrm{IU} \cdot \mathrm{L}^{-1}$ (serum 398, normal 230-460). Lipoprotein electrophoresis demonstrated cholesterol esters, phospholipids, sphingomyelins, free fatty acids and neutral fats in the form of chylomicra. Oil red $\mathrm{O}$ and Sudan black staining confirmed the chylous nature of the effusions. Chemical analysis of the diagnostic pericardiocentesis also revealed chyle with a triglyceride content of $216 \mathrm{mg} \cdot \mathrm{dL}^{-1}$ and a cholesterol content of $44 \mathrm{mg} \cdot \mathrm{dL}^{-1}$. Lipoprotein analysis of the pericardial fluid revealed chylomicra. Breast ultrasonography showed low dermal echogenicity, interpreted as intradermal oedema with a skin thickness of $18 \mathrm{~mm}$. In normal skin, the upper dermis $(100 \mu \mathrm{m})$ is only slightly less echogenic than the lower dermis $(300 \mu \mathrm{m})$.

Filariasis was considered, but no filariae were identified in the sera and nocturnal blood samples. No schistosoma eggs were found in the stools and the enzyme-linked immunosorbent assay for Toxocara canis was negative.

Malignant cells were identified in both the pleural effusions and the chylopericardium, staining positively with periodic acid-Schiff (PAS)-alcian blue and diastase-PAS (d-PAS) stains (fig. 2). These cells were positive for car-
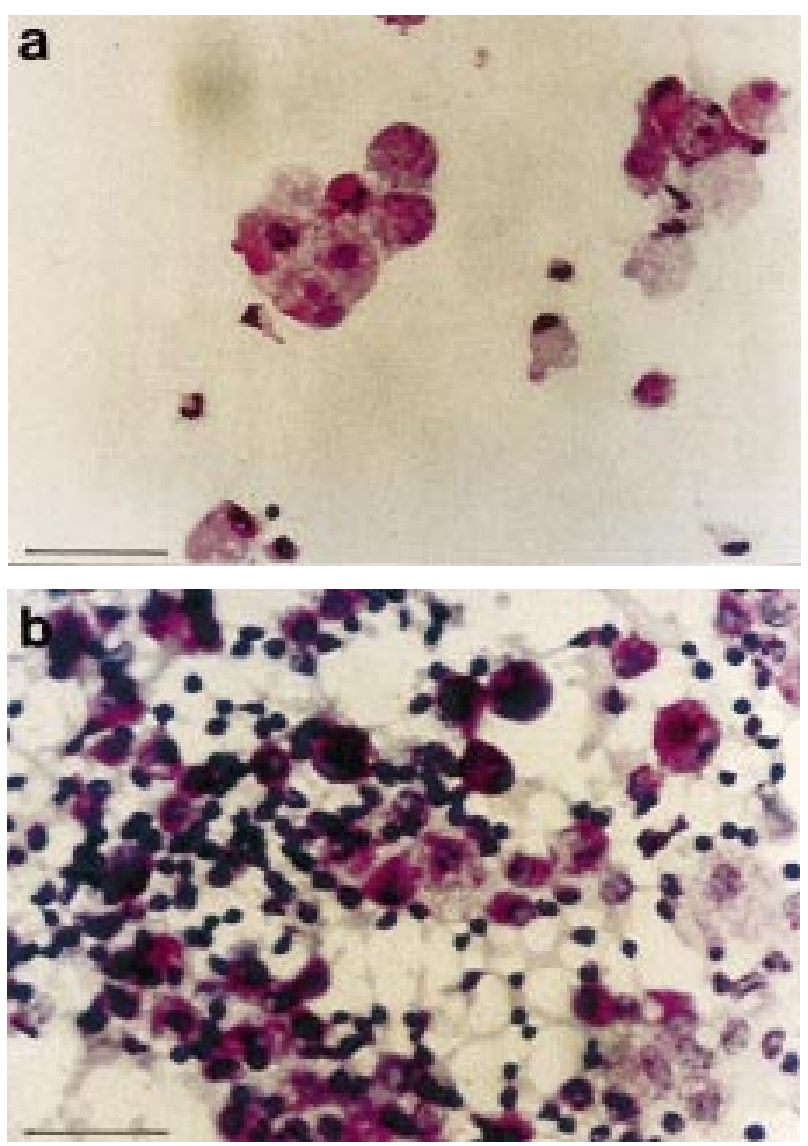

Fig. 2. - Cytopathological appearance of the pleural effusion demonstrating malignant cells staining positively with: a) haematoxylin and eosin; and b) diastase-periodic acid-Schiff stains. (Internal scale bars = $50 \mu \mathrm{m}$. cinoembryonic antigen (CEA) and cytokeratin and were negative for L-26 (CD20 - pan- $\beta$ cell marker) and UCHL1 (T-cell marker). Tumour markers in the pleural effusions included: CEA $200 \mathrm{ng} \cdot \mathrm{mL}^{-1}$ (normal 0-7.0), CA125 $447,000 \mathrm{IU} \cdot \mathrm{L}^{-1}$ (normal <35,000), CA19-9 240,000 IU $\cdot \mathrm{L}^{-1}$ (normal $<37,000$ ).

The patient required repeated bilateral thoracocentesis for the relief of dyspnoea. Initially, a low-fat diet and repeated therapeutic taps resulted in an improvement in her dyspnoea, but, over the ensuing days, her symptoms became refractory, despite thoracocentesis two or three times per week. A total of $12 \mathrm{~L}$ of chyle was aspirated over a 3week period. A Denver pleuroperitoneal shunt (Denver Biomaterial, Golden, CO, USA) was then inserted on the right side, 35 days after presentation. The right-sided chylothorax was successfully managed by means of the Denver pleuroperitoneal shunt. Chest tube drainage was completed on the left side 55 days after presentation; 17 days after insertion of the chest tube, when the fluid diminished to 60 $\mathrm{mL}$ daily, a tetracycline pleurodesis was performed.

Two months following presentation, the patient developed multiple cervical lymph nodes. A left cervical lymph node and a random skin biopsy from the abdominal wall (fig. 3) confirmed signet-ring cell carcinoma infiltration. Mucicarmine and d-PAS staining demonstrated cytoplasmic mucin in the tumour cells. Although endoscopic and radiological investigations of the gastrointestinal tract were negative, a well-defined, uniloculated cyst measuring $4 \times 5 \mathrm{~cm}$ between the uterus and rectum was detected
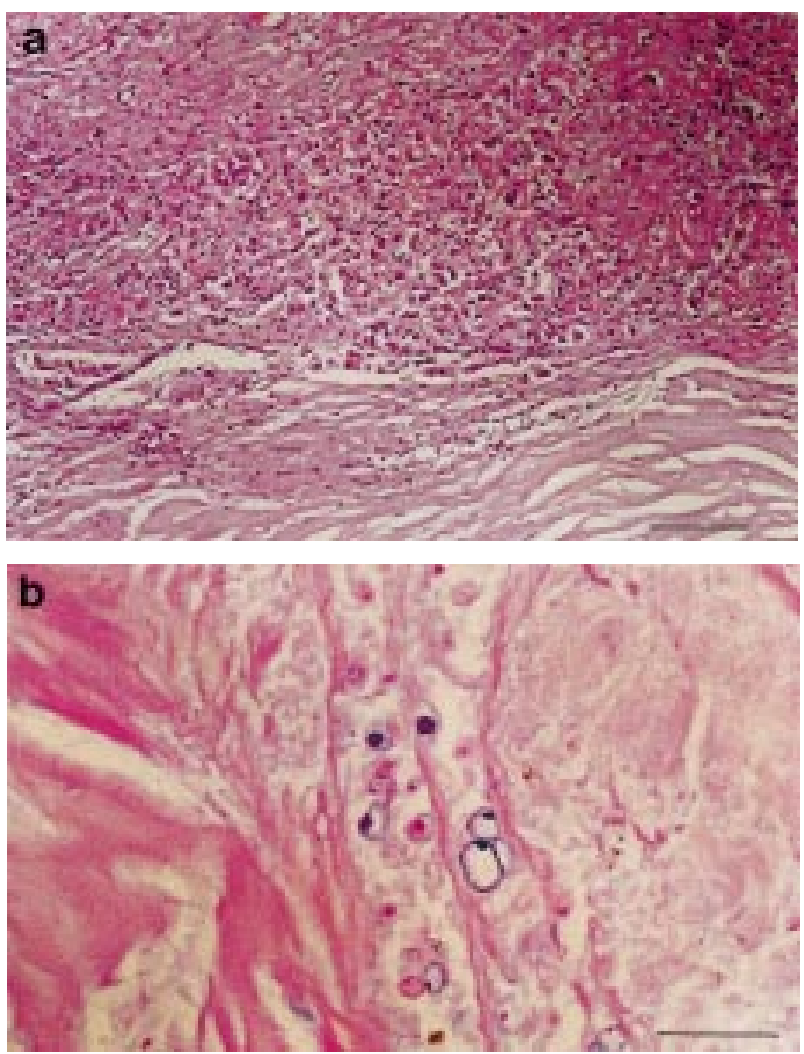

Fig. 3. - Micrographs of the skin biopsy. a) Junction of dermis and subcutis showing infiltration by metastatic carcinoma (haematoxylin and eosin stain). (Internal scale bar=100 $\mu \mathrm{m}$.) b) Cutaneous metastatic carcinoma showing a signet-ring cell morphology (diastase-periodic acidSchiff-alcian blue stain). (Internal scale bars $=50 \mu \mathrm{m}$.) 
by means of CT examination of the abdomen. This finding was absent on an abdominal CT scan taken 6 months earlier as part of a lymphoedema investigative procedure. However, the patient and family refused any further investigation, therapy or surgical intervention.

Despite medical support, including a low-fat diet, the patient died 3.5 months after presentation, having remained an inpatient for the entire period. A post mortem was refused.

\section{Discussion}

This study reports a rare case, remarkable not only because of the bilateral malignant chylous pleural and pericardial effusions, but also because of the association with skin infiltration caused by signet-ring cell carcinoma resembling elephantiasis.

Chylothorax is a rare primary or secondary condition, the commonest cause of which is trauma, either following surgery of the oesophagus or great vessels or following penetrating wounds or hyperextension of the spine [1-4]. Non-traumatic chylothorax secondary to filariasis, postinflammatory thoracic duct obstruction, idiopathic lymphangiectasis with lymph node hypoplasia, malignancy, subclavian vein thrombosis or lymphangioma are much less common $[5,7,8]$. Bilateral chylous effusions do occur and are associated with a poor prognosis [1]. The probable mechanism of chylothorax in this patient is lymphatic obstruction caused by tumour cells, resulting in dilatation and ectasia of lymph channels.

Treatment of chylothorax is difficult. Tube drainage and chemical pleurodesis in combination with a low-fat, medium-chain triglyceride diet to reduce chyle flow and total parenteral nutrition are often considered to be the initial approach. Most authors recommend a period of no more than 2-3 weeks of tube drainage and total parenteral nutrition. Surgical treatment by means of pleurectomy or ligation of the thoracic duct is indicated if conservative treatment fails. In the present patient, the chylothoraces were initially managed with repeated thoracocentesis, a low-fat diet and total parenteral nutrition. In view of the failure of this management, a Denver pleuroperitoneal shunt was placed on the right, and tube drainage and tetracycline pleurodesis were completed on the left. A repeat echocardiogram showed no reaccumulation of pericardial effusion. Initially, the patient gained symptom relief, but 3 weeks later, she suffered from recurrent effusion on the left despite talc pleurodesis and died 3.5 months after presentation, never being sufficiently well for hospital discharge.

When chylothorax is secondary to malignant disease, treatment of the primary condition with radiotherapy and/ or chemotherapy may relieve the thoracic duct obstruction sufficiently to prevent any reaccumulation of the effusion. The primary site of signet-ring cell carcinoma in this patient is not known. Treatment including chemotherapy was considered. Only palliative treatment, however, was accepted by the patient and her family.

The incidence of cutaneous infiltration from internal malignancies has been estimated in autopsy studies to be between 0.6 and $4.4 \%$ of all cases of malignant disease (lymphoma and leukaemia excluded) [9-13]. The occurrence of elephantiasis-like cutaneous infiltration from signet-ring cell carcinoma is extremely rare, and, to the best of the authors' knowledge, this is the second such case reported [14]. The association of chylothorax and chylopericardium with gross oedema of the skin due to signet-ring cell carcinoma infiltration has not been previously reported.

This patient represents the first report of severe lymphoedema resulting from a signet-ring cell carcinoma in association with bilateral chylothorax and chylopericardium.

\footnotetext{
Acknowledgements. The authors would like to thank J.J. Egan, P.W. Bishop and H. Anderson of Wythenshawe Hospital, Manchester for correcting the English text and valuable discussions concerning the case.
}

\section{References}

1. Merrigan BA, Winter DC, O'Sullivan GC. Chylothorax. Br J Surg 1997; 84: 15-20.

2. Miller JI Jr. Diagnosis and management of chylothorax. Chest Surg Clin N Am 1996; 6: 139-148.

3. Browse NL, Allen DR, Wilson NM. Management of chylothorax. Br J Surg 1997; 84: 1711-1716.

4. Ramzy IA, Rodriguez A, Cowley RA. Pitfalls in the management of traumatic chylothorax. J Trauma 1982; 22: 513-551.

5. Bresser P, Kromhout JG, Reekers JA, Verhage TL. Chylous pleural effusion associated with primary lymphedema and lymphangioma-like malformations. Chest 1993; 103: 1916-1918.

6. Stirling CM, Boulton-Jones JM, Simpson K. Progressive oedema in a 30-year old. Lancet 1998; 352: 450.

7. Oak SN, Kulkarni BK, Deshmukh H, Kamble M, Borwankar SS. Chylothorax: a conservative approach (a case report). J Postgrad Med 1991; 37: 223-224.

8. Kitchen ND, Hocken DB, Greenhalgh RM, Kaplan DK. Use of the Denver pleuroperitoneal shunt in the treatment of chylothorax secondary to filariasis. Thorax 1991; 46: 144-145.

9. Brownstein MH, Helwig EB. Metastatic tumors of the skin. Cancer 1972; 29: 1298-1307.

10. Feuerman EJ, Nir MA, Lurie M. Delayed cutaneous metastases of mucus producing cell carcinoma of the stomach. Dermatologica 1973; 146: 15-20.

11. Alonso-LIamazares J, De Pablo P, Ballestin C, Guerra A, Iglesias L. Cutaneous metastasis from a presumed signetring cell carcinoma in a 10-year-old child. Br J Dermatol 1998; 138: 145-149.

12. Miyashita M, Honjo M, Suzuki H, et al. A case of cutaneous metastases of gastric carcinoma showing peculiar clinical features. J Dermatol 1991; 18: 619-623.

13. Vidmar D, Baxter DL Jr, Devaney K. Extensive dermal metastases from primary signet-ring carcinoma of the urinary bladder. Cutis 1992; 49: 324-328.

14. Heidenheim M, Hansen U, Andersen J. Elephantiasis-like cutaneous metastases from signet ring cell carcinoma of the stomach. Cutis 1989; 44: 451-454. 